\title{
Mechanism of action in CBT (MAC): methods of a multi-center randomized controlled trial in 369 patients with panic disorder and agoraphobia
}

\author{
A. T. Gloster, H. U. Wittchen, F. Einsle, M. Höfler, T. Lang, S. Helbig-Lang, T. Fydrich, L. \\ Fehm, A. O. Hamm, J. Richter, G. W. Alpers, A. L. Gerlach, A. Ströhle, T. Kircher, J. Deckert, \\ P. Zwanzger, V. Arolt
}

\begin{abstract}
Cognitive behavioral therapy (CBT) is efficacious for panic disorder with agoraphobia (PD/A). Nevertheless, the active ingredients of treatment and the mechanisms through which CBT achieves its effects remain largely unknown. The mechanisms of action in CBT (MAC) study was established to investigate these questions in 369 patients diagnosed with PD/A. The MAC study utilized a multicenter, randomized controlled design, with two active treatment conditions in which the administration of exposure was varied, and a wait-list control group. The special feature of MAC is the way in which imbedded experimental, psychophysiological, and neurobiological paradigms were included to elucidate therapeutic and psychopathological processes. This paper describes the aims and goals of the MAC study and the methods utilized to achieve them. All aspects of the research design (e.g., assessments, treatment, experimental procedures) were implemented so as to facilitate the detection of active therapeutic components, and the mediators and moderators of therapeutic change. To this end, clinical, behavioral, physiological, experimental, and genetic data were collected and will be integrated.
\end{abstract}

Keywords Panic disorder, Agoraphobia, CBT, Exposure therapy, Mechanisms, Methods

\section{Theoretical background}

Cognitive behavioral therapy (CBT) across its many variations is efficacious for a wide range of mental disorders, with particularly strong effects for panic disorder and agoraphobia (PD/A) [5, 33, 36]. Despite the clear empirical support for CBT, numerous issues remain unclear. Primary among these is determining the mechanisms of action that lead to meaningful therapeutic change. The significance of identifying the active ingredients and mechanisms involved in the therapeutic process is manifold, with direct implications for the delivery of treatment, prediction of treatment response, understanding of factors that maintain therapeutic effects, and revealing possibilities for improvement of CBT as a psychotherapeutic method. Indeed, identification of the most relevant active ingredients and the core mechanisms involved in therapeutic improvement has implications for the definition of CBT itself.

As evidenced by numerous theoretical debates, the time is ripe to better understand what CBT is, what it changes, and how those changes are achieved [4, 30, 46]. To obtain such an understanding, a research design is needed that goes a step beyond those used in traditional efficacy trials. This means that an understanding of how CBT works necessitates the assessment of numerous factors not normally considered, and the more factors considered, the larger the required sample size. The mechanisms of action (MAC) study for panic and agoraphobia was established as a starting point to address these questions using a whole range of clinical and basic methods. 
At the molar level (i.e., variables and constructs defined at a higher level of abstraction relative to lower-level molecular variables and constructs) hypotheses regarding possible mechanisms of therapeutic action abound [43]. They range from change in self-efficacy, to changes in "cognitive" constellations, to more precise hypotheses derived from learning theory such as habituation and extinction $[15,16,36]$. Fewer hypotheses exist at the molecular level, in part because the identification of therapeutic processes has seldom been a part of this research tradition. That said, preliminary research has implicated neural networks such as the so-called "fear circuitry" [18, 26, 27], the influence of functional genetic polymorphisms including the gene coding for the serotonin transporter protein [22, 23, 35], and psychophysiological processes [37]. Embedded in a large state-of-the art research platform, the MAC specifically targets molar variables in the form of objective and subjective ratings, molecular genetic variables, and those in-between of physiological measurements and functional magnetic resonance imaging (fMRI) approaches. Contrary to previous research, however, the MAC was structured such that the large number of dynamically interacting variables and levels can begin to be unraveled through the identification of salient processes that moderate and mediate treatment outcome. Emphasis in the first phase of the program was put upon the identification of active ingredients of CBT most likely involved in promoting therapeutic change.

Primary candidates for salient variables include the frequency, intensity, and type of administration of exposure in vivo exercises (i.e., under therapists guidance versus administration of intense cognitive exercises intended to induce behavioral change). Consistent with the available evidence, both variants of CBT are hypothesized to result in alterations of patients' cognitive appraisals and a reduction of panic and agoraphobia symptoms. Hypothesized differences between these two CBT variants relate to the speed, persuasiveness, and stability of changes as well as expectations that distal and proximal patient characteristics will be associated with differential treatment outcomes. Thus, the first aim of the MAC is to examine to what degree CBT with explicit exposure in vivo under therapist guidance outside the therapy room results in different changes as compared to a CBT variant where the therapist attempts to implement the same exercises without leaving the therapy room with the patient for the actual in vivo exposure exercises. Following an examination of the overall effectiveness of these two CBT variants (active tx) versus a wait list control group, the second phase of the research program will produce finer-grained analyses of putative mechanisms of change and the identification of predictors for sustained response and remission.

With these goals in mind, the MAC established a standardized treatment protocol and manual [34] utilized with all patients as a spring board from which to determine how therapeutic processes and outcomes are associated. In particular, the MAC targeted (a) learning processes involved in the startle reaction, anticipatory anxiety, and associated autonomic responses; (b) the processing of anxiety-relevant stimuli using paradigms of exteroceptive and interoceptive perception and conditioning/extinction; and (c) genetic variations.

Given that the MAC represents one of the first attempts to bridge traditionally isolated areas of research, it is worthwhile and necessary to examine the methods utilized and, en route, to clarify terms. It is to this task that we now turn our attention beginning with a description of the clinical trial concluding with experimental paradigms. 


\section{Methods of the overarching clinical trial}

\section{Research design}

The MAC is a randomized, multicenter, clinical treatment outcome study with 369 outpatients who met DSM-IV criteria for panic disorder and agoraphobia. The study design was structured so that measures of treatment course and outcome could be related to specific treatment components. All patients were randomized to two active CBT treatment variants and a wait-list control group (WL). The distinguishing feature between otherwise identical CBT variants dealt with the administration of the exposure in vivo. The first active CBT condition included some sessions in which the therapist provided active guidance in exposure outside the therapy room (therapist guided exposure $\mathrm{T}+$ ), whereas in the second active CBT condition the therapist was confined to the therapy room (no therapist guided T-).

\section{Procedure}

\section{Patient recruitment, inclusion and exclusion criteria}

Eight treatment centers in Germany participated (Aachen, Berlin-Adlershof, Berlin-Charité, Bremen, Dresden, Greifswald, Münster, Würzburg). Participants were recruited from ongoing clinical mental health care (i.e., 3 psychiatric clinics and 5 clinical psychological outpatient centers), physician referral (e.g., primary care physicians, neurologists, psychiatrists, cardiologists), and via additional advertisements in various media outlets (e.g., newspapers, internet, television). Participants who screened positive for the inclusion criteria were given an appointment to obtain written informed consent. Those who agreed to partake in the study scheduled a diagnostic appointment to determine whether all inclusionary criteria were met.

Inclusion criteria consisted of: (a) a current primary diagnosis of panic disorder and agoraphobia (PD/A) (as defined by the criteria of the diagnostic and statistical manual, fourth revision/text revision (DSM-IV-TR) [2] validated by a standardized computer-administered personal Composite International Diagnostic Interview (CAPI-WHO-CIDI; DIAX-CIDI version [47]); (b) a clinical interview score C18 on the structured interview guide for the Hamilton anxiety scale (SIGH-A [44] in anxiety and depression); (c) a score C4 on the clinical global impressions scale (CGI) [28]; (d) age 18-65 years; (e) ability and availability to regularly attend treatment sessions. The flow of patients into the study can be seen in Fig. 1. Nineteen patients from the WL were re-randomized to one of the active treatment conditions following the waitlist period. These patients met all inclusion criteria at the time of re-randomization.

Compared to previous studies, exclusion criteria were minimal to allow for the inclusion of patients with comorbid conditions commonly seen in daily practice. Exclusion criteria were (a) comorbid DSM-IV-TR psychotic or bipolar I disorder; (b) current alcohol dependence/current abuse or dependence for benzodiazepine and other psychoactive substances; (c) current suicidal intent, (d) borderline personality disorder, (e) concurrent ongoing psychotherapeutic or psychopharmacological treatment for PD/A or another mental disorder; (f) antidepressant or anxiolytic pharmacotherapy; (g) physician-verified contraindications of exposure-based CBT (i.e., severe cardiovascular, renal, and neurological diseases). The frequencies with which patients were not allocated to treatment because of these inclusion and exclusion criteria are listed in Table 1. As can be seen in Table 1, most patients were excluded because their scores on the clinical rating scales were too low, thus suggesting that the patients in the MAC are relatively severely affected. 


\section{Sample characteristics}

Table 2 describes the sociodemographic characteristics of the 369 patients enrolled. The sample consisted overwhelmingly of patients with psychiatric comorbid conditions, with a mean of 3.5 comorbid diagnoses. Only $7.9 \%$ had no other diagnoses, whereas additional diagnoses were present as follows: 1-2 comorbid diagnoses (44.7\%), 3-4 (33.9\%), and 5 or more comorbid diagnoses (13.6\%). The most frequent comorbid diagnoses were: specific phobias (69.4\%), social phobia (41.7\%), major depression (35.2\%), harmful use of alcohol (37.4\%), pain disorder (34.2\%), and generalized anxiety disorder (20.3\%).

\section{Assessment}

Assessments occurred at five primary time points chosen to capture changes in putative active ingredients in the treatment process (see Table 3): diagnostic (before inclusion), baseline (before treatment), intermediate (after the fourth session), post (immediately following treatment), and follow-up (6 months after the end of treatment). Each treatment session included a number of additional assessments, partly embedded within the therapy itself and tightly linked to add on studies. A description of the utilized measures can be seen in „Appendix”. Patients in the WL group took part in all assessments from baseline to posttreatment.

Primary outcome parameters targeted domains of global anxiety and panic/agoraphobicspecific symptomatology [31]. These were assessed using both interview-rated outcome measures [SIGH-A total score (range 0-56) and the CGI (range 1-7)] and questionnaires completed by the patients assessing panic attacks [panic and agoraphobic scale (PAS) -mean number of panic attacks in the past week (subscale range $0-4$ )] and agoraphobic avoidance [mobility inventory original version (MI)]—mean of the alone subscale (range 1-5)]. Secondary outcomes were included to assess additional domains and answer secondary questions (see Table 3; Appendix). Among these, several behavioral measures (i.e., the amount of time the patient remained in the behavioral avoidance test, the frequency of exposures, duration of exposures, and distress experienced during exposures) were recorded.

Patients additionally completed self-monitoring forms throughout the treatment, especially before and after each exposure exercise. Prior to the exposure patients recorded information about the situation and anticipatory anxiety. Following the exposure, patients recorded the course of anxiety during the exercise, any use of safety behaviors, and their subjective conclusions regarding the exercise. Therapists separately recorded all safety behaviors utilized by the patient during the exercise.

\section{Data collection and database}

Assessments were directly entered by patients into an internet-based computer interface. Missing data were minimal due to the use of programmed algorithms that informed the interviewer and the patient of any missing data and prompted completion before continuing (around 2\% across all items and assessments). Patients were trained by their therapist in the use of the computer program. All data was linked with the corresponding login password so that every change of the database was time-stamped and could be tracked. The database was saved at a central data coordinating center (study coordination center; KKS Dresden) that also insured data security. The database was checked regularly and the time of entry was compared against the scheduled entry time. Therapists and clinical directors of each center received regular feedback about the quality and timeliness of data for each of their patients. 


\section{Treatment}

\section{Treatment procedure}

Therapy consisted of 12 individual sessions conducted over approximately 8 weeks. The therapy was implemented twice weekly with each session lasting approximately $100 \mathrm{~min}$. The therapy was based on established manuals [15] previously evaluated as effective for patients with PD/A in several clinical trials [8] and developments in exposure-based CBT [6, 38, 42]. Based on these existing manual components a study manual-optimized for the study rationale and for component analyses-was written by experts for exposure therapy [34]. The manual focused on a clear differentiation between different techniques of exposure therapy as a basis for a better understanding of the mechanisms of action as well as an optimal separation between $\mathrm{T}+$ and $\mathrm{T}$-. It is again important to note that both active therapy variants $\mathrm{T}+$ and $\mathrm{T}$ contained exactly the same ingredients, were of identical duration, and differed only in the manner in which the exposure was implemented in vivo (therapist guided, supervised, and intensified vs. no therapist present during in vivo exposure exercises).

The manual was highly structured and detailed to minimize between-therapist variability. Details were conveyed in multiple levels (e.g., session overview, guiding principles, session take-home message, aims, session-specific exercises and forms). It included detailed descriptions of each procedure, provided sample dialogues, and anticipated typical problems with guidance for solutions. Figure 2 highlights the main components of each session.

The first treatment phase (sessions 1-5) was identical in both conditions (e.g., establishing therapeutic rapport, psycho-education, self-monitoring, functional analysis, interoceptive exposure). Only sessions 6-8 and 10-11 differed between the groups with respect to the implementation of exposure ( $\mathrm{T}+$ and $\mathrm{T}-)$. Although the $\mathrm{T}$-condition discussed various aspects of exposure including barriers to effective implementation, no formal cognitive restructuring or disputation of thought content was implemented. Patients in both treatment groups were instructed to engage in three standardized exposure exercises (bus, department store, forest) followed by two individualized situations. In the $\mathrm{T}+$ condition, exercises were carried out during the session with the therapist present. Prior to the next session, the patient was instructed to repeat this exposure exercise two more times. Patients in the T-group were instructed to complete three self-exposures between these sessions, thus holding the assigned number of exposure exercises constant between the two conditions. Quantification of all initiated exposures, whether assigned or not, were recorded at the next session in terms of the frequency, duration and experienced distress of all exposures. All self-exposures were reviewed in the following session in both conditions.

In both active treatment conditions, two booster sessions (sessions 13-14) were conducted. These sessions reviewed progress, addressed avoidance behavior-especially in stressful situations - and discussed additional exposure exercises that the patient could practice.

\section{Manual training, certification of therapists, and supervision}

All therapists were trained by experts in exposure-based CBT for P/A. All therapists were qualified at least at the level of advanced graduate student status in clinical psychology. Content of the manual was trained over a 3-day intensive and interactive course followed by a recorded role-play graded by experts. Therapists were only allowed to see study patients after 
passing the role-play examination. Of 89 therapists trained in these procedures, 75 were certified as study therapists.

During this psychotherapy study, all therapists were involved in weekly manual specific supervision in their respective study center. Supervision was supplanted with a weekly telephone conference involving all centers in which problems with the manual and the study protocol were discussed.

\section{Therapy integrity}

All sessions were recorded on video cassettes or DVD. All violations of the protocol were documented and reported to the study coordination centers. Therapy integrity was assessed by independent raters. Over $15 \%$ of all sessions $(n=724 / 4,214=17.2 \%)$ were randomly selected and analyzed using the therapist adherence and competence rating scale for panic disorder and agoraphobia [24]. All raters took part in a two day training procedure and passed a qualification exam. The exam consisted of two videos, each of which had to be rated within one point of the expert rating on each item.

\section{Core experimental components}

\section{Behavioral avoidance test}

A behavioral avoidance test (BAT; darkroom paradigm) was executed at pre, intermediate, post, and follow-up in all patients to explore changes in symptom reports of avoidance behavior and physiological responding during anticipation (sitting $10 \mathrm{~min}$ in front of the cabinet) and exposure $(10 \mathrm{~min})$ in a narrow $(120975 \mathrm{~cm})$ and dark room. The administration of this test aims to explore the mechanism of innervations at the behavioral and psychophysiological level [1]. Skin conductance and heart rate were obtained as measures of autonomic arousal while startle responses to acoustic probes (surface electromyography recordings over the left orbicularis oculi muscle) were measured as an index of subcortically mediated defense mobilization. Prior to therapy, 68\% of all patients stayed in the dark room for the entire $10 \mathrm{~min} .20 \%$ of the patients, however, escaped from the dark room with an average duration of $4 \mathrm{~min}$. 12\% of the patients refused to enter the dark and were thus categorized as avoiders. Overall, patients experienced 45 panic attacks within the dark room, with no differences between escapers and non-escapers. Overall, the heart rate was increased during exposure for escapers compared to non-escapers suggesting that increased physiological arousal might predict behavioral avoidance. On the other hand, those patients in the non-escaper group who reported comparably high levels of anxiety during exposure as the escapers also had significantly increased heart rates but did not leave the room.

\section{Psychophysiological subtypes}

In order to explore the value of respiratory and vestibular panic subtypes in the overall study, a subset of patients underwent two biological challenges [3]. In order to measure vestibular sensitivity, different visual flow stimuli were presented through a head-mounted display, thereby inducing a conflict between visual input and somatosensory information [32]. Anxiety and dizziness were assessed repeatedly by means of self-reports, while resultant body sway was measured continuously with a force plate that individuals stood on. In order to measure respiratory sensitivity, we measured responses to a hypoxic $(12 \% \mathrm{O} 2)$ and a hypercapnic (7.5\% CO2) laboratory challenge while measuring tidal volume, respiratory rate, the end-tidal $\mathrm{CO} 2$ concentration in the exhaled air, anxiety, and panic symptoms. The observed 
physiological reactions will be related to previously identified latent class factors [3] with the aim of clarifying the impact of differential symptomatology on treatment efficacy, and to determine to what extent treatment should be tailored to these subtypes.

\section{Fear circuitry mechanisms}

Using three paradigms (aversive conditioning, interoception vs. exteroception, and anticipation of panic-relevant stimuli) before and after treatment, this project examines changes in the fear circuitry mechanisms associated with panic disorder and agoraphobia and potential activation pattern of treatment response [10].

\section{Genetic variation and prediction}

Functional risk polymorphisms for panic disorder such as those of the serotonin transporter, the monoamine oxidase or catecholamine-o-methyltransferase genes [19] or for novel genetic risk polymorphisms derived from animal models such as a neuropeptide $\mathrm{S}$ receptor gene polymorphism will be explored. Intermediate phenotypes for panic disorder will be examined under the premise that these correlate better with biological parameters like genetic variations. For example, heart rate in the BAT will be correlated to a functional polymorphism in the serotonin $1 \mathrm{~A}$ receptor gene to determine whether this genetic variant exerts some of its effect via modulating vegetative parameters [21]. Additionally, genome-wide approaches will be utilized to define hitherto unknown genetic variants which increase the risk for panic disorder and/or influencing the therapeutic response to cognitive behavioral therapy.

\section{Conclusion}

MAC is a state-of-the-art collaborative and interdisciplinary research platform from which the mechanisms of therapeutic action in exposure-based CBT for patients with panic disorder and agoraphobia will be investigated. MAC promises to offer insights about a range of issues. The data will provide information about how variations in exposure-based CBT differentially affect a range of behavioral, cognitive, affective, and physiological outcomes. Necessary, salient, inactive, and even iatrogenic components can be identified and related to courses of symptomatology, maintenance of therapeutic gains, and relapse. In turn, the dynamic relationship between these results and molecular variables as well as variables from a systems-neuroscientific approach will be examined with the prospect of identifying moderator and mediator variables. Finally, MAC will generate hypotheses that will lead to a number of experiments that will focus on specific mechanisms of disease and therapeutic action. Evidence is already emerging that the sum total of the findings expected from MAC will significantly contribute to our understanding of the mechanisms of action in CBT. 


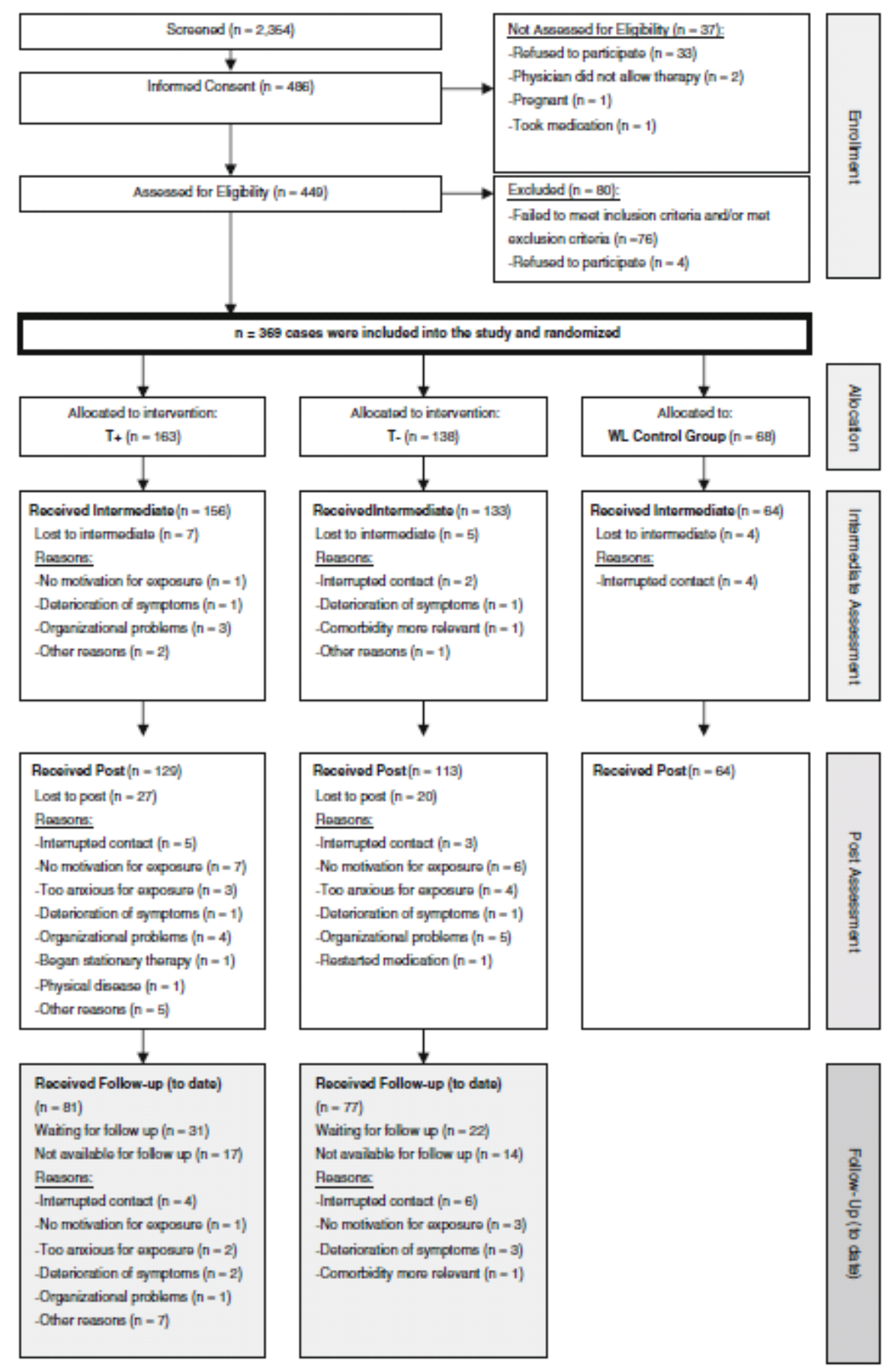

Fig 1 Consont flowehart of the MAC randomized control psychotherapy study 


\begin{tabular}{|c|c|}
\hline $\begin{array}{l}\text { Therapist Guided Exposure } \\
\qquad(\mathrm{T}+)\end{array}$ & $\begin{array}{l}\text { No Therapist Guided } \\
\text { (T-) }\end{array}$ \\
\hline \multicolumn{2}{|c|}{ Sessions 1-3: Psychoeducation } \\
\hline \multicolumn{2}{|c|}{ Sessions 4-5: Interoceptive exposure; Thought experiment } \\
\hline $\begin{array}{l}\text { Sessions 6-8: Exposure in vivo with the therapist } \\
\text { in standard situations: bus, department store, } \\
\text { forest }\end{array}$ & $\begin{array}{l}\text { Session 6-8: Guidance for self-exposure in vivo } \\
\text { in standard situations: bus, department store, } \\
\text { forest }\end{array}$ \\
\hline \multicolumn{2}{|c|}{ Session 9: Anticipatory anxiety } \\
\hline $\begin{array}{l}\text { Sessions 10-11: Exposure in vivo with the } \\
\text { therapist in ideographically salient situations }\end{array}$ & $\begin{array}{l}\text { Session 10-11: Guidance for self-exposure in } \\
\text { vivo in ideographically salient situations }\end{array}$ \\
\hline \multicolumn{2}{|c|}{$\begin{array}{l}\text { Sessions 12: Discussion of therapeutic gains and individual plans for continued exposure exercises } \\
\text { during booster period; relapse prevention }\end{array}$} \\
\hline Booster 1-2: Discussion of individual expo & re during booster period; relapse prevention \\
\hline
\end{tabular}

Fig 2 Overview of the therapy content in the active treatment conditions

Table 1 Reasons why patients assersed for eligibility were nok allocated to treatment

\begin{tabular}{lcc}
\hline & $N$ & $\%$ of 80 \\
\hline Failed wo meet inclusion criteris & 0 & 0 \\
Age & 15 & 18.8 \\
Panic disorder & 16 & 20.0 \\
Agoraphobia & 45 & 56.3 \\
HAMA $\geq 18$ & 14 & 17.5 \\
CGI $\geq 4$ & 1 & 1.3 \\
Schedule & & \\
Met exclusion criveria & 13 & 16.3 \\
Unahle to comply with the study protocol & 0 & 0.0 \\
Suicidal intent & 0 & 0.0 \\
Bipolar & 2 & 2.5 \\
Psychosis & 0 & 0.0 \\
Borderline & 6 & 7.5 \\
Other axis I & 2 & 2.5 \\
Alochol dependence & 4 & 5.0 \\
Other medical explanation for symptoms & 4 \\
\hline
\end{tabular}

Calegories do not total $100 \%$ because multiple responses were possible 


\section{Table 2 Sample characteristics $(n=369)$}

\begin{tabular}{|c|c|c|}
\hline & Mesin & SD \\
\hline \multirow[t]{2}{*}{ Age } & 35.5 & $(10.8)$ \\
\hline & $n$ & $\%$ \\
\hline \multicolumn{3}{|l|}{ Gender } \\
\hline Make & 87 & 23.6 \\
\hline Femsle & 282 & 76.4 \\
\hline \multicolumn{3}{|l|}{ Years of education } \\
\hline 8 & 43 & 11.7 \\
\hline 10 & 165 & 44.7 \\
\hline $12-13+$ & 150 & $\$ 0.7$ \\
\hline No formal degree & 11 & 3.0 \\
\hline \multicolumn{3}{|l|}{ Living arr angement } \\
\hline With parents & 19 & 5.2 \\
\hline Alone & 70 & 19.0 \\
\hline With partner & 258 & 69.9 \\
\hline Other & 22 & 6.0 \\
\hline \multicolumn{3}{|l|}{ Employment } \\
\hline University student & 16 & 4.3 \\
\hline Job training & 98 & 26.6 \\
\hline Employed & 218 & $\$ 9.1$ \\
\hline Unemployed & 34 & 9.2 \\
\hline Other & 3 & 0.8 \\
\hline \multicolumn{3}{|l|}{ Social class } \\
\hline Lowest & 18 & 5.0 \\
\hline Lower midale & 81 & 22.4 \\
\hline Middle & 223 & 61.8 \\
\hline Upper midsle & 39 & 10.8 \\
\hline Upper & 0 & 0.0 \\
\hline \multicolumn{3}{|l|}{ Marital status } \\
\hline Married & 117 & 31.8 \\
\hline $\begin{array}{l}\text { Divorced/widowed } \\
\text { separaled }\end{array}$ & so & 13.6 \\
\hline Never married & 201 & 54.6 \\
\hline
\end{tabular}

Some variables do not total $100 \%$ due to missing yalues 


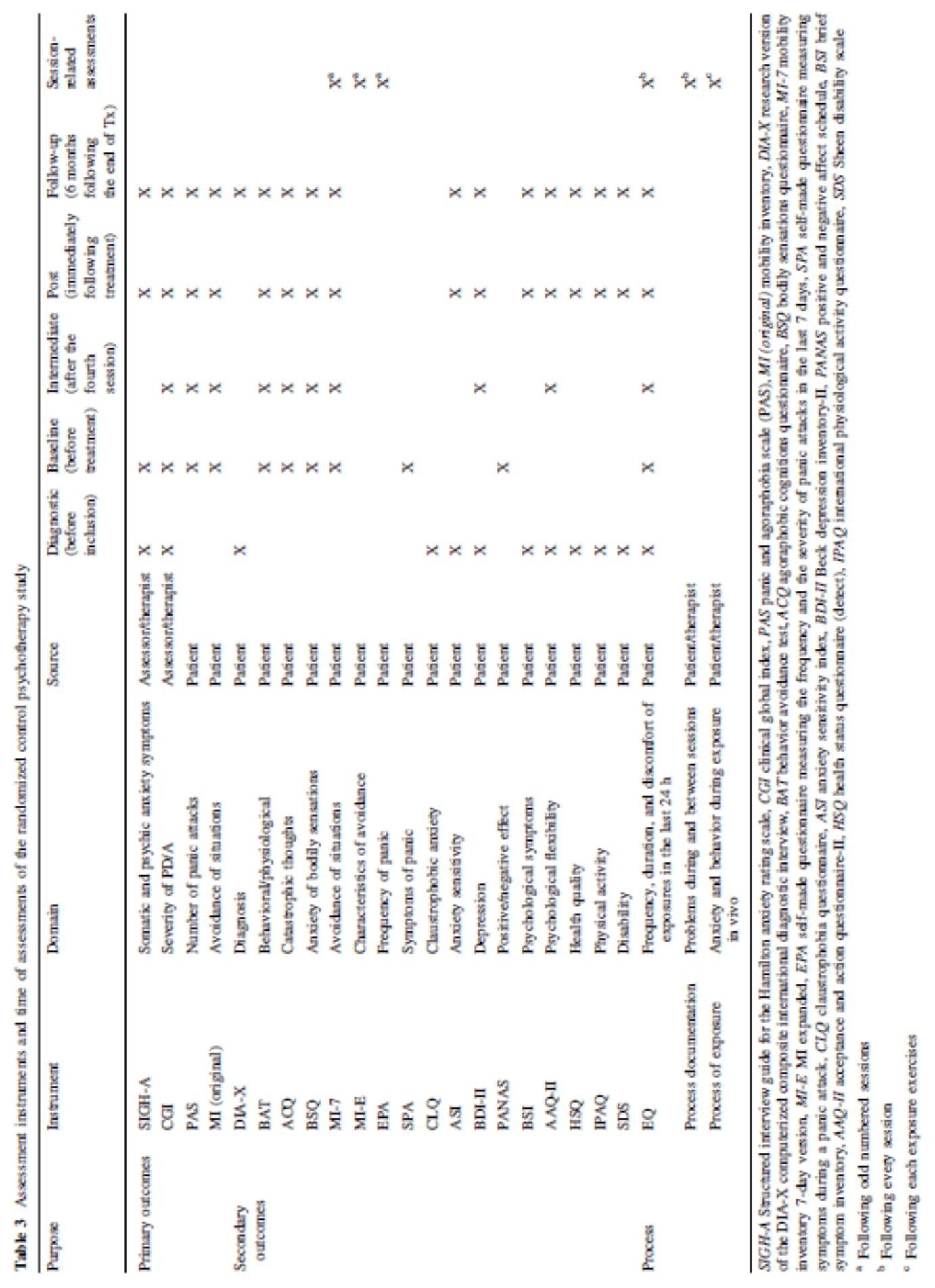


Appendix: Description of assessment instruments of the randomized control psychotherapy study

\begin{tabular}{|c|c|}
\hline Abtreviation & Description \\
\hline SIGH-A (HAMA) & $\begin{array}{l}\text { The Hamilson Anxiery Scale [29] is a 14-item lest measuring the severity of anxiety symptoms. Each item is rated on a five- } \\
\text { point scale (range: } 0-\text { not present to } 4-\text { severe) by the therapist interviewing the patient }\end{array}$ \\
\hline CGI & $\begin{array}{l}\text { The Clinical Gbbad Impression Scale [28] anchored for panic disorder is comple ted by the therapist to rate the severity of } \\
\text { the patient's disorder and the ther apeutic improvement. It yields five different measures: (1) the severity of patient's } \\
\text { current symptomatology, (2) the extent of anxiety, (3) the extent of avoidance behavior, (4) the global functioning, and } \\
\text { (5) an overall score. Each item is rated on a seven-point seak from } 1 \text { (normal) to } 7 \text { (amongst the most severely ill } \\
\text { patients) }\end{array}$ \\
\hline PAS & $\begin{array}{l}\text { The Panic and Agaraphobin Scale [7] is a } 13 \text {-ikm questionnaire that refers to the past week and assesses the extent of the } \\
\text { severity of panic discrder as well as the existence and severity of agoraphohia by collecting information on } \\
\text { phenomenology, frequency and severity of typical symphoms, e.g., panic atbeks, anticipatory arxiety and avoidance } \\
\text { behavior. All items were five-point scaled and scored from } 0 \text { to } 4 \text { as well }\end{array}$ \\
\hline MI (original) & $\begin{array}{l}\text { The Mobility Invensory [12] is part of the questionnaire of body related fears, cognitions and avoidance and comprises } 27 \\
\text { items regarding avoidance in specific situations with or without accompaniment by a trust person. Each item is rated by } \\
\text { patients on a five-point scale, ranging from } 1 \text { (never avoid) to } 5 \text { (always avoid) }\end{array}$ \\
\hline DLA $-X$ & $\begin{array}{l}\text { The Research Vension of the DIA-X computerized Composite Internutional Diagnostic Interview [47] is a fully } \\
\text { standardized diagnostic interview assesing symptoms and diagnosis of mental disorders by information about } \\
\text { impaiment, onset, duration and severity. Disorder-specific symptom lists and cognitive aids support the participant in } \\
\text { answering questions }\end{array}$ \\
\hline $\mathrm{ACQ}$ & 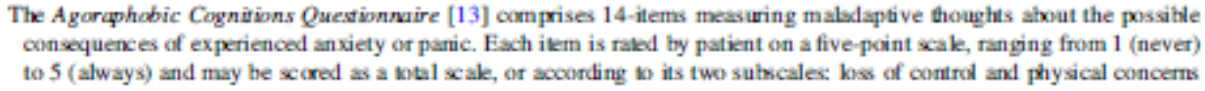 \\
\hline BSQ & $\begin{array}{l}\text { The Body Senvafions Questicnnaire [13] comprises } 17 \text { items measuring frightened feelings of body sensation occurring in } \\
\text { nervous or feared situations. Fach item is rated by patient on a five-point scale, ranging from } 1 \text { (not at all) to } 5 \\
\text { (extremely) }\end{array}$ \\
\hline MI-7 & $\begin{array}{l}\text { The Mobility Inventory. } 7 \text { days }([25] \text { is an adapted version of the Mobility Inventory and was developed for use in this } \\
\text { study. The Ml-7 days comprises } 27 \text { items regarding avoidance in specific situations with or without acoompaniment by a } \\
\text { trus person. Each item is rated by patients on a five-point scake, ranging from } 1 \text { (never avoid) to } 5 \text { (always avoid) }\end{array}$ \\
\hline MIE & $\begin{array}{l}\text { The Mobility Inventory- Expanded [25] comprises } 27 \text { items measuring frequency and arxiety in and importance of } \\
\text { situations in the last } 7 \text { days. Each item is rated by patient on frequency of occurrence and five-point scales of anxiety and } \\
\text { importance, ranging from } 0 \text { (not at all) to } 4 \text { (extremely) }\end{array}$ \\
\hline EPA & $\begin{array}{l}\text { The Evaluation of Panic Arsack questionnaire is a self-designed 3-item self-report measuring the frequency and the severity } \\
\text { of panic attacks in the bas } 7 \text { days. Symptoms of the worst and bowest panic attack are delected }\end{array}$ \\
\hline SPA & $\begin{array}{l}\text { The Symptoms of a Pani: Arsuck questionnaire is a self-designed self-report. The first } 10 \text { items measure the kind and } \\
\text { extension of bodily symptoms during panic atbcks and are rated on a five-point anxiety scale ranging from } 0 \text { (not at all) } \\
\text { to } 4 \text { (extremely). The other part involves three ilems measuring the frequency of visiting arxiety related situations and the } \\
\text { level of streas in the last } 24 \mathrm{~h}\end{array}$ \\
\hline CLQ & $\begin{array}{l}\text { The Chussirophobia Questionnaire [90] is a } 26 \text {-item self-report measurement assessing confinement and suffocation } \\
\text { concerns relevant to claustrophohia. Each item is rated on a five-point anxiety scale ranging from } 0 \text { (not at all) io } 4 \\
\text { (extremely) }\end{array}$ \\
\hline ASI & $\begin{array}{l}\text { The Anxiety Sensitivity Index [41] is a } 16 \text {-item self-report measuring subjects beliefs about potential harmf ul consequences } \\
\text { of anxiety rebated symphoms. Each item is rated on a five-point scale from } 0 \text { (very little) to } 4 \text { (very much) }\end{array}$ \\
\hline BDI-II & $\begin{array}{l}\text { The Beck Depression Inventory- } I I[9] \text { is a } 21 \text {-item self-report measuring severity of symptoms associated with depression. } \\
19 \text { items are rated on a four-point scale, } 2 \text { further ilems are assessed on a sevne-point scale }\end{array}$ \\
\hline
\end{tabular}

Appendix continued

\begin{tabular}{ll}
\hline Abtreviation & Description \\
\hline PANAS & The Positive and Negative Affect Schedule [17] is a 20-item self-report measuring the extent of differemt feelings and
\end{tabular}

PANAS The Posinive and Neyative Affect Schedule [17] is a 20-ikem self-report measuring the extent of differemt feelings and emotions over the last days. Each word and phrase is rated on a five-point scale ranging from 0 (not at all) to 4 (extremely)

BSI The Brief Symptom Inventory [20] is a 53-item self-report symptom inventory assessing the psychological symptom patterns of prychiatric and medical patients and non-patients over the past week. Each item is rated on a five-point scale from 0 (not at all) to 4 (extremely)

AAQII The Acceptance and Action Questionnaire [11] is a 10-item self-report measure of prychological flexibility and acceptance. Each item is rated on a seven point scale from 1 (never true) to 7 (always true)

HSQ (EQ5) The Heath Status Questionnaire [39] is a 12-item self report measuring the current state of health. One part of the HSQ consists of the EQ-SD involving five dimensions of health: mobility, self-care, ususl activities, pain/discomfort, and anxiety/depression. Each dimension is assessed on three levels of severity: 1 = no problems; 2 = moderate problems; and 3 = extreme problems. The other part comprises ilems re garding daily restrictions based on the status of health, frequency of consultation, intake of drugs and problems with handling health

IPAQ The Intemational Physical Activity Questionnaire-long form [14] is a self-report measuring a 7-day recall of habitual practice of physical activities divided into five parts: at work, at travel, in and around the house, in leisure time and sitting time

SDS The Sheean Disability Scale [45] is a 3-item self report assessing functional impsirment in work, social and family life, ltems are raled on a 11 point scale transbted into a percentage from 0 (not at all) to $100 \%$ (extremely)

EQ The Exposure Quantification Scale is a self-developed scale consisting of three questions that measure the frequency, duration and associaled discomfort of exposure exercises implemented by the patients, irrespective of whether or not they were assigned exercises or spontaneou 


\section{References}

1. Alpers GW, Sell R (2008) And yet they correlate: psychophysiological measures predict the outcome of exposure therapy in claustrophobia. J Anxiety Disord 22:1101-1109

2. American Psychiatric Association (2000) Diagnostic and statistic manual of mental disorders, text revision, 4th edn. American Psychiatric Association, Washington, DC

3. Andor F, Glöckner-Rist A, Gerlach AL, Rist F (2008) Symptomspezifische Subgruppen der Panikstörung. Zeitschrift für Klinische Psychologie und Psychotherapie 37:161-171

4. Arch JJ, Craske MG (2008) Acceptance and commitment therapy and cognitive behavioral therapy for anxiety disorders: different treatments, similar mechanisms? Clin Psychol Sci Pract 15:263-279

5. Arch JJ, Craske MG (2009) First-line treatment: a critical appraisal of cognitive behavioral therapy developments and alternatives. Psychiatr Clin North America 32:525-547

6. Baker-Morrissette S, Spiegel DA, Heinrichs N (2005) Sensation-focused intensive treatment for panic disorder with moderate to severe agoraphobia. Cogn Behav Pract 12:17-29

7. Bandelow B (1999) Panic and agoraphobia scale (PAS). Hogrefe \& Huber Publishers, Ashland

8. Barlow DH, Gorman JM, Shear MK, Woods SW(2000) Cognitive-behavioral therapy, imipramine, or their combination for panic disorder — a randomized controlled trial. JAMA 283:2529-2536

9. Beck AT, Steer RA, Brown GK (1996) Manual for the BDI-II. The Psychological Corporation, San Antonio

10. Blümel I, Jansen A, Kellermann T, Schüppen A, Kohn N, Gerlach A et al. (2009) Neural correlates of aversive conditioning (submitted)

11. Bond FW, Hayes SC, Baer RA, Carpenter KM, Orcutt HK, Waltz T et al. (2007) Preliminary psychometric properties of the acceptance and action questionnaire-II: a revised measure of psychological flexibility and acceptance (in review)

12. Chambless DL (1985) The mobility inventory for agoraphobia. Behav Res Ther 23:35-44

13. Chambless DL, Caputo GC, Bright P, Gallagher R (1984) Assessment of fear of fear in agoraphobics: the body sensations questionnaire and the agoraphobic cognitions questionnaire. $\mathrm{J}$

Consult Clin Psychol 52:1090-1097

14. Craig CL, Marshall AL, Sjostrom M, Bauman AE, Booth ML, Ainsworth BE et al (2003) International physical activity questionnaire: 12 -country reliability and validity. Med Sci Sports Exerc 35:1381-1395

15. Craske MG, Barlow DH (2007) Mastery of your anxiety and panic. University Press, Oxford 16. Craske MG, Kircanski K, Zelikowsky M, Mystkowski J, Chowdhury N, Baker A (2008) Optimizing inhibitory learning during exposure therapy. Behav Res Ther 46:5-27

17. Crawford JR, Henry JD (2004) The positive and negative affect schedule (PANAS): construct validity, measurement properties and normative data in a large non-clinical sample. British Journal of Clinical Psychology 43:245-265

18. Davis M (2006) Neural systems involved in fear and anxiety measured with fear-potentiated startle. Am Psychol 61:741-756

19. Deckert J, Catalano M, Syagailo Y, Bosi M, Okladnova O, Di Bella D et al (1999) Excess of high activity monoamine oxidase A gene promoter alleles in female patients with panic disorder. Hum Mol Genet 8:621-624

20. Derogatis LR (1993) Brief symptom inventory (BSI) administration, scoring, and procedures manual, 3rd edn. National Computer Systems, Minneapolis

21. Domschke K, Braun M, Ohrmann P, Suslow T, Kugel H, Bauer J et al (2006) Association of the functional -1019C/G 5-HT1A polymorphism with prefrontal and amygdala activation measured with 3T fMRI in panic disorder. Int J Neuropsychopharmacol 9:349-355

22. Domschke K, Hohoff C, Jacob C, Maier W, Fritze J, Bandelow B et al (2008) Chromosome 4q3134 panic disorder risk locus: association of neuropeptide Y Y5 receptor variants. Am J Med Genet B Neuropsychiatr Genet 147B:510-516

23. Domschke K, Ohrmann P, Braun M, Suslow T, Bauer J, Hohoff C et al (2008) Influence of the catechol-O-methyltransferase val158met genotype on amygdala and prefrontal cortex emotional processing in panic disorder. Psychiatry Res 163:13-20

24. Gloster A, Einsle F, Lang T, Hauke T, Wittchen H-U (2009) The therapist adherence and competency rating scales for panic disorder with agoraphobia (in preparation) 
25. Gloster AT, Klotsche J, Helbig S, Einsle F, Lang T, Hummel K et al. (2009) Expanding the assessment domain in agoraphobia: mobility inventory-expanded (MI-E) and mobility inventory 7-day (MI-7) versions (in preparation)

26. Gorman JM, Kent JM, Sullivan GM, Coplan JD (2000) Neuro-anatomical hypothesis of panic disorder, revised. Am J Psychiatry 157:493-505

27. Gorman JM, Liebowitz MR, Fyer AJ, Stein J (1989) A neuro-anatomical hypothesis for panic disorder. Am J Psychiatry 146:148-161

28. Guy W (1976) Clinical global impression. In: Guy W (ed) ECDEU assessment manual for psychopharmacology, revised. National Insitute of Mental Health, Rockville, pp 217-222

29. Hamilton M (1959) The assessment of anxiety states by rating. Br J Med Psychol 32:50-55

30. Hayes SC (2008) Climbing our hills: a beginning conversation on the comparison of acceptance and commitment therapy and traditional cognitive behavioral therapy. Clin Psychol Sci Pract 15:286295

31. Hofmann SG, Alpers GW, Pauli P (2009) Phenomenology of panic and phobic disorders. In: Antony MM, Stein MB (eds) Oxford handbook of anxiety and related disorders. Oxford University Press, New York, pp 34-46

32. Hueweler R, Kandil FI, Alpers GW, Gerlach AL (2009) The impact of visual flow stimuli on anxiety, dizziness, and body sway in persons with and without fear of heights. Behav Res Therapy 47:345-352

33. Koch EI, Gloster AT, Waller SA (2007) Exposure treatments for panic disorder with and without agoraphobia. In: Richard DCS, Lauterbach DL (eds) Handbook of exposure therapies. Elsevier, Burlington, pp 221-245

34. Lang T, Helbig-Lang S, Westphal D, Gloster AT, Wittchen HU (2009) Kognitiv-behaviorale Behandlung der Panikstörung mit Agoraphobie. Ein Therapiemanual. Hogrefe, Göttingen

35. Lonsdorf TB, Weike AI, Nikamo P, Schalling M, Hamm AO, Öhman A (2009) Genetic gating of human fear learning and extinction-Possible implications for gene-environment interaction in anxiety disorder. Psychol Sci 20:198-206

36. McHugh RK, Smits JAJ, Otto MW (2009) Empirically supported treatments for panic disorder. Psychiatr Clin North Am

37. Melzig CA, Michalowski JM, Holtz K, Hamm AO (2008) Anticipation of interoceptive threat in highly anxiety sensitive persons. Behav Res Ther 46:1126-1134

38. Neudeck P, Wittchen H-U (2005) Die Vernachlässigung der Expositionsverfahren- ein Verstoß gegen die Regeln der Kunst!. In: Neudeck P, Wittchen H-U (eds) Konfrontationstherapie bei psychischen Störungen. Hogrefe, Göttingen, pp 7-14

39. Rabin R, de Charro F (1999, 2001) EQ-5D: a measure of health status from the EuroQol Group. Paper presented at the 12th Medical Symposium of the Yrjo-Jahnsson-Foundation, Finland 40. Radomsky AS, Rachman S, Thordarsona DS, McIsaaca HK, Teachman BA (1999) The claustrophobia questionnaire. J Anxiety Disord 15:287-297

41. Reiss S, Peterson RA, Gursky DM, McNally RJ (1986) Anxiety sensitivity, anxiety frequency and the prediction of fearfulness. Behav Res Therapy 24:1-8

42. Richard DCS, Lauterbach D, Gloster AT (2007) Description, mechanisms of action, and assessment. In: Richard DCS, Lauterbach DL (eds) Handbook of exposure therapies. Elsevier, Burlington, pp 1-28

43. Shadish WR, Cook TD, Campbell DT (2002) Experimental and quasi-experimental designs for generalized causal inference. Houghton-Mifflin, Boston

44. Shear MK, Vander Bilt J, Rucci P, Endicott J, Lydiard B, Otto MW et al (2001) Reliability and validity of a structured interview guide for the Hamilton anxiety rating scale (SIGH-A). Depress

Anxiety 13(4):166-178

45. Sheehan DV (1983) The anxiety disease. Charles Scribner's Sons, New York

46. Wittchen H-U, Gloster AT (2009) Developments in the treatment and diagnosis of anxiety disorders. Psychiatr Clin North Am 32:xix-xiii

47. Wittchen H-U, Pfister H (1997) DIA-X Interview. Instruktionsmanual zur Durchführung von DIA$\mathrm{X}$-Interviews (Instruction manual for the DIA-X-Interview). Swets \& Zeitlinger, Frankfurt 